Journal of Engineering and Applied Sciences 14 (5): 1498-1509, 2019

ISSN: 1816-949X

(C) Medwell Journals, 2019

\title{
Energy and Exergy Analysis of Magnetohydrodynamic Nuclear Fission Reactor (MHD-NFR) Cycle
}

\author{
${ }^{1}$ Alireza Shayestehnezhad, ${ }^{2}$ Shahram Khalilarya and ${ }^{2}$ Samad Jafamadar \\ ${ }^{1}$ Department of Mechanical Engineering, Urmia University, Urmia, Iran \\ ${ }^{2}$ Department of Mechanical Engineering, Faculty of Engineering, Urmia University, Urmia, Iran
}

\begin{abstract}
This study aims at investigating closed-cycle MHD power plant with individual unit capacity of 250 MW and using helium and xenon mixture as a working gas. The heat source required to produce the gas flow supplied by the nuclear fission reactor. Using mass, energy and exergy balance equations all cycle equipment have been analyzed individually and energy efficiency, exergy efficiency and irreversibility has been calculated for each of them as required. The results of the analysis show that the maximum efficiency of the first and second law of the cycle at a nominal load of $250 \mathrm{MW}$ with a temperature output of $2300 \mathrm{~K}$ and enthalpy extraction $34.79 \%$ using a Faraday MHD generator are $51.17 \%$. Paying more attention to the exergy destruction ratio is about $48.83 \%$ of the exergy entering in CCMHD cycles. Hence, the remaining $51.17 \%$ is converted to power. The MHD generator in this case is the most important cause of exergy destruction in cycle about $20 \%$. Effects of compressor stage number, regenerator efficiency and cooler operating temperature on plant efficiency were studied.
\end{abstract}

Key words: Energy, exergy, Faraday, MHD, NFR, heat

\section{INTRODUCTION}

In the past years, electric power has been generated using conventional systems such as thermal, hydro and nuclear plants. In these systems, most of the energy obtained during the combustion of fossil fuel is firstly converted into mechanical energy before being converted into electrical energy. The electric power generated from these plants requires huge capital costs and often raises several environmental concerns through the pollution they constantly yield. Additionally, the output efficiency that can be realized from these systems is about 40-45\% (Kaushik et al., 1995; Masood et al., 2014; Ayeleso et al., 2015). For the past 50 years, many researchers have been thinking of new energy alternatives and methods that can help to improve the overall efficiency of the conventional power plants. One of such methods is to incorporate to the existing plants a topping unit such as a Magneto Hydro Dynamic, MHD system which is a direct energy conversion system (Vishal and Anand, 2013).

In recent years, the study of MHD flow and its effect on power generation in the related systems, received considerable attention because of its importance in industries as mentioned in the above. Here, several works have been mentioned in which the effect of MHD flow on power generation for various flows and geometries is investigated (Kotas, 1985; Mozafari et al., 2009).
Salas et al. (1999) analyzed the second law for MHD induction devices such as electromagnetic pumps and electrical generators. In addition to irreversibilities created by viscous dissipation and heat and mass transfer they considered the irreversibility due to Joule dissipation generated by electric currents circulating in the conducting fluid. Ibanez et al. (2002) optimized the operation conditions an alternate $\mathrm{MHD}$ generator based on the global entropy generation rate. Aiboud and Saouli (Smrekar et al., 2009) demonstrated the application of the second law analysis of thermodynamics to viscoelastic MHD flow over a stretching surface. Mohagheghi and Shayegan (2009) proposed a new method for modeling a steam cycle in advanced combined cycles by organizing nonlinear equations and their simultaneous solutions by using the hybrid Newton methods. They also calculated an optimal thermodynamic performance conditions for heat recovery steam generator using GA (Genetic Algorithm). Meanwhile, Aiboud and Saouli (2010) have presented the ANN Models using real plant data in order to predict the fresh steam properties from a brown coal-fired boiler of a Slovenian power plant. Rashidi et al. (2011) presented a parametric study for and optimization of a transcritical power cycle. In their study, thermal efficiency, exergy efficiency and specific network were selected as objective functions for parametric optimization. They proposed a procedure in order to

Corresponding Author: Alireza Shayestehnezhad, Department of Mechanical Engineering, Urmia University, Urmia, Iran 
optimize these functions based on combination of GA and ANN. Mahian et al. (2012) analyzed the first and second laws of thermodynamics to illustrate the effects of MHD flow on the distributions of velocity, temperature and entropy generation between two concentric rotating cylinders. Rashidi et al. (2013) presented the study of all concerns the first and second law analysis of an electrically conducting fluid past a rotating disk in the presence of a uniform vertical magnetic field.

In the recent years, thermodynamic analysis for MHD bypass engines has proved that the idea is correct (Bityurin et al., 2000; Kaminaga et al., 2005; Benyo, 2010). However, due to the multiplicity and complexity of MHD system and restricted by present technology there still exist many problems to settle, especially for MHD power generation. The Institute of Electrical Engineering, Chinese Academy of Sciences conducted open cycle coal MHD power generation experiments in the 1980 s and the $\mathrm{K}_{2} \mathrm{CO}_{3}$ solution was used in their experiment ( $\mathrm{Ju}$ et al., 1998). Chen et al. (2002) The analytical expressions for the power output and the efficiency have been derived for the $\mathrm{MHD}$ plant coupled to variable temperature heat reservoirs at constant gas velocity and constant mach number conditions. Their results showed that there exists an optimum pressure ratio corresponding to the maximum power output and an optimum pressure ratio corresponding to the maximum efficiency for both the constant velocity and constant Mach number cases. Kayukawa (2004) studied on alternative MHD topping combined systems are reviewed and the predominance of these systems over the gas turbine combined cycles is emphasized. The importance of a regeneration and recirculation scheme for an efficient thermal cycle was shown and a stand-alone-scheme of open-cycle MHD power generation system is proposed where in high efficiency, $\mathrm{CO}_{2}$ liquefaction and a wide range of combustion temperature selectivity are emphasized. Nob. Chandra and Pandey (2005) Some preliminary investigations have been presented in this study liquid metal MHD power conversion systems have recently been proposed for direct electrical energy conversion of low grade thermal source of energy, light solar energy and waste heat. Such systems can be used for generating hydrogen by electrolysis of water.

Litchford and Harada (2011) studied on closed cycle $\mathrm{MHD}$ power generation system for space application. System analysis was carried out. Total plant efficiency was expected to be $55.2 \%$ including pre-ionization power. Effects of compressor stage number, regenerator efficiency and radiation cooler temperature on plant efficiency were studied. Specific mass of power generation plant was examined. Yiwen et al. (2011) presented a preliminary experimental investigation on Magneto Hydro Dynamic (MHD) power generation using seeded supersonic helium flow as working fluid. They reported that under the optimized condition when load factor was 0.5 , the maximum power density of the MHD power generation channel reached $4.7971 \mathrm{MW} / \mathrm{m}^{3}$ and the maximum enthalpy extraction rate was $0.34 \%$. Cicconardi and Perna (2014) Presented two plant configurations based on open-cycle MHD generators fed with coal. Their results showed that high system efficiencies (up to 60\%) can be achieved by using the syngas due to a better heat recovery in the high temperature region. Ayeleso and Kahn (2017) investigated through simulations and theoretical modelling two existing Open-Cycle Gas Turbines (OCGT) in South Africa which can be converted into Combined-Cycle MHD Gas-Steam Turbines (CCMGST). Their results showed that high system efficiencies (up to $50 \%$ ) can be achieved.

System description: The MHD conversion system was initially discovered by Michael Faraday and later extended on a small scale by Ayeleso and Kahn (2017), Malghan (1996). In this system, the conductive fluid (natural gas, plasma) is injected from a heating source and flow through an expansion nozzle at high velocity before entering the MHD duct. Inside the MHD duct, the fluid becomes ionized and their velocity is decelerated by a strong magnetic field, $\mathrm{B}$ which creates a retarding force (Lorentz force) that is perpendicular to the direction of the fluid. The resulting positive and negative ions of the ionized fluid are then collected by the electrodes placed at 90 to the induced magnetic field, thus, producing an electric current (Ebadi and Gorji-Bandpy, 2005; Aoki et al., 2012).

In order to utilize the waste heat from CCMHD system and improve the performance of this cycle three novel combined cycles producing power were proposed and discussed in detail. In all these cycles, organic Rankine cycles were employed. The details of proposed cycles are as follows:

The Closed-Cycle MHD (CCMHD): As depicted in Fig. 1, in the closed-cycle system, the inert gas is heated by a NFR (about $2300 \mathrm{~K}$ ) and seeded with cesium vapor to get ionized. The ionized gas then flows through the MHD duct to produce DC power. The exhaust hot gas from the $\mathrm{MHD}$ duct is recovered and recycled to produce more steam through HRVG. The MHD system consists of 6 main components: a recuperator a Nuclear Fission Reactor 




Fig. 1: Schematic diagrams of basic CCMHD

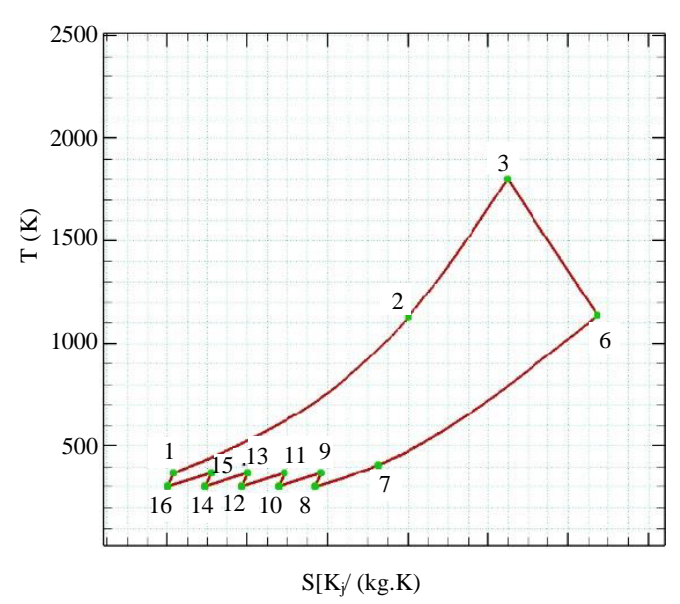

Fig. 2: A simplified T-S diagram of the CCMHD power plant

(NFR) a MHD duct a cooler and a compressor and an intercooler and 5 main thermodynamic processes: isobaric heating in the recuperator and NFR, isentropic expansion in the expander, isobaric cooling in the cooler and isentropic compression in the compressor. For better comparison, T-S diagrams are illustrated for the two combined cycles (Fig. 2).

Thermodynamic analysis: A thermodynamic model was developed for the closed-MHD is outlined in this part.
This model is an extension of a previous research presented by the researchers (Chandra and Pandey, 2005). The model basically comprises the mass, energy and exergy balances considering the design constraints. Solution to these equations and the thermodynamic properties relations in the computer program will simulate the cycle performance (Bejan et al., 1996). Before elaborating the mathematical models, the assumptions used are given as follows (Chandra and Pandey, 2005; Cicconardi and Perna, 2014; Klein and Alvarda, 2007):

- The CCMHD power plants operate in a steadystate condition

- The pressure drops throughout the pipelines are neglected

- The effectiveness was considered for intercooler, recuperator and cooler

- The CCMHD compressor have isentropic efficiencies

- The kinetic and potential energy changes are neglected

Meanwhile, Table 1 and 2 summarizes the input parameter values for the proposed combined cycles.

Energy analysis: To find the optimum physical and thermal design parameters of the system a simulation program was developed with EES Software. The gas 
Table 1: Expressions for exergy destruction rate and exergy efficiency for cycle components

\begin{tabular}{|c|c|c|}
\hline Plant component & Exergy destruction rate & Exergy efficiency \\
\hline $\begin{array}{l}\text { Helium } \\
\text { compressor }\end{array}$ & $\dot{\mathrm{E}}_{\mathrm{xi}}-\dot{\mathrm{E}}_{\mathrm{xe}}+\dot{\mathrm{W}}_{\text {Comp }}$ & $\dot{\mathrm{E}}_{\mathrm{xe}}-\dot{\mathrm{E}}_{\mathrm{xi}}$ \\
\hline NFR & $\dot{\mathrm{E}}_{\mathrm{xi}}-\dot{\mathrm{E}}_{\mathrm{xe}}+\left[1-\frac{\mathrm{T}_{0}}{\mathrm{~T}_{\mathrm{r}}}\right] \dot{\mathrm{Q}}_{\mathrm{NFR}}$ & $\begin{array}{l}\mathrm{W}_{\text {Corpp }} \\
\dot{\text { Ex }_{\text {DestCC }}} \\
\dot{\dot{Q}}\end{array}$ \\
\hline MHD duct & $\dot{\mathrm{E}}_{\mathrm{xi}}-\dot{\mathrm{E}}_{\mathrm{xe}}-\mathrm{PO}_{\mathrm{MHD}}$ & $\begin{array}{l}\mathrm{Q}_{\mathrm{NFR}} \\
\mathrm{PO}_{\mathrm{MHD}} \\
\end{array}$ \\
\hline Recuperator & $\sum_{\text {irec }} \dot{\mathrm{E} x}-\sum_{\mathrm{e} e \mathrm{erc}} \dot{\mathrm{E} x}$ & $\begin{array}{l}\dot{\mathrm{Ex}}_{\text {Dest.MHD }} \\
\dot{\mathrm{Ex}}_{\mathrm{c} . \mathrm{e}}-\mathrm{Ex} \cdot \mathrm{Ex}_{\mathrm{c} . \mathrm{I}}\end{array}$ \\
\hline Cooler & $\sum_{\mathrm{i} P \mathrm{EC}} \dot{\mathrm{Ex}}-\sum_{\mathrm{e} \mathrm{PC}}^{\mathrm{e} P \mathrm{EC}} \dot{\mathrm{Ex}}$ &  \\
\hline Intercooler & $\sum_{\text {i.IC }} \dot{\mathrm{E} x}-\sum_{\mathrm{e} . \mathrm{IC}} \dot{\mathrm{Ex}}$ & $\begin{array}{l}\sum \mathrm{Ex}_{\mathrm{iPC}} \\
\dot{\mathrm{E} \mathrm{x}_{\text {DestIC }}} \\
\sum \dot{\mathrm{E} \mathrm{x}_{\mathrm{iIC}}}\end{array}$ \\
\hline
\end{tabular}

Table 2: Baseline performance characteristics

\begin{tabular}{ll}
\hline Parameters & Values \\
\hline NFR & \\
Thermal output power & $5(\mathrm{MWth})$ \\
Reactor output temperature & $1800(\mathrm{~K})$ \\
Reactor output pressure & $0.4(\mathrm{MPa})$ \\
Pressure loss & $2.5 \%$ \\
MHD generator & \\
Enthalpy extraction & $35 \%$ \\
Isentropic efficiency & $80 \%$ \\
Compressor & \\
Heat loss & $1 \%$ \\
Isentropic efficiency & $85 \%$ \\
Pressure loss & $1 \%$ \\
Number of stages & $1-6$ stages \\
Radiation cooler & \\
Temperature & $300(\mathrm{~K})$ \\
Pressure loss & $1 \%$ \\
Regener ator & \\
Efficiency & $100 \%$ \\
Heat loss and pressure loss & $1 \%$ \\
Pre-ionizer & \\
Efficiency & $50 \%$ \\
System analysis summary & \\
Thermal input to MHD generator & $12.89(\mathrm{MWth})$ \\
Electric output power & $4.51(\mathrm{MWe})$ \\
Compressor power & $1.67(\mathrm{MWe})$ \\
Pre-ionization power & $0.08(\mathrm{MWe})$ \\
Net output electrical power & $2.76(\mathrm{MWe})$ \\
Total first law efficiency & $55.2 \%$ \\
\hline
\end{tabular}

temperature profiles in a closed-MHD and the input and output enthalpy and exergy of each line in the plant were estimated in the multi-objective optimization of the plant. Energy balances and governing equation for various $\mathrm{CCMHD}$ and CCMHD/ORC combined cycle components are as follows:

\section{CCMHD Model}

Helium compressor: Helium with pressure $P_{i}$ and Temperature $\mathrm{T}_{\mathrm{i}}$ enters the compressor. The compressor outlet temperature is a function of compressor isentropic efficiency $\left(\eta_{\mathrm{AC}}\right)$, compressor pressure ratio $\left(\mathrm{r}_{\mathrm{AC}}\right)$ and helium specific heat ratio $(\gamma)$ as follows (Klein and Alvarda, 2007; Dincer and Rosen, 2007):

$$
\mathrm{T}_{\mathrm{e}}=\mathrm{T}_{\mathrm{i}}\left(1+\frac{1}{\eta_{\mathrm{AC}}}\left[\left(\mathrm{r}_{\mathrm{AC}}\right)^{\frac{\gamma-1}{\gamma}}-1\right]\right)
$$

The compressor work rate is a function of helium mass flow rate $\left(\dot{\mathrm{m}}_{\mathrm{He}}\right)$ helium specific heat and temperature difference and can be expressed as follows:

$$
\dot{\mathrm{W}}_{\text {comp }}=\dot{\mathrm{m}}_{\mathrm{He}} \mathrm{C}_{\mathrm{p}}\left(\mathrm{T}_{\mathrm{e}}-\mathrm{T}_{\mathrm{i}}\right)
$$

where, $\mathrm{C}_{\mathrm{p}}$ is heat capacity in constant pressure. The second to sixth stage compressor can also be analyzed in a similar way.

Nuclear Fission Reactor (NFR): The outlet properties of the NFR are a function of helium mass flow rate, heat power of NFR as follows:

$$
\dot{\mathrm{Q}}_{\mathrm{NFR}}=\dot{\mathrm{m}}_{\mathrm{He}}\left(\mathrm{h}_{\mathrm{e} \cdot \mathrm{NFR}}-\mathrm{h}_{\mathrm{i} . \mathrm{NFR}}\right)
$$

The NFR outlet pressure is defined by considering a pressure drop across the NFR as follows:

$$
\frac{P_{e}}{P_{i}}=(1-\Delta P)
$$

Where:

$\mathrm{P} \quad=$ The Pressure loss across the

NFR and $\dot{\mathrm{Q}}=$ The thermal heat power

MHD duct: According to the law of electromagnetic induction when the velocity of the conductor is $\mathrm{u}$, the induction parameter is $\mathrm{B}$ and the load factor is $\mathrm{K}$, the electrical field strength $\mathrm{E}$ is (Yiwen et al., 2011; Sun et al., 2017; Rosa, 1987):

$$
\mathrm{E}=\mathrm{KuB}
$$

where, $\mathrm{K}$ is the ratio between the load resistance of generator $\mathrm{R}$ and total resistance ( $\mathrm{R}$ and intrinsic resistance $\mathrm{R}_{\mathrm{i}}$ ) and $\mathrm{K}<1$ :

$$
\mathrm{K}=\frac{\mathrm{R}}{\mathrm{R}+\mathrm{R}_{\mathrm{i}}}=\frac{\mathrm{E}}{\mathrm{uB}}
$$

The current density J (Modified Ohm 's Law ) created by induced electromotive force is:

$$
\mathrm{J}=\sigma(\mathrm{uB}-\mathrm{E})=(1-\mathrm{K}) \sigma \mathrm{uB}
$$

The conductivity $\sigma$ can be calculated with the voltage and current profile and the power density $\mathrm{P}$ is described as: 


$$
\mathrm{P}=\mathrm{JE}=\mathrm{K}(1-\mathrm{K}) \sigma \mathrm{u}^{2} \mathrm{~B}^{2}
$$

The enthalpy extraction rate can be used to describe the efficiency of MHD generating tunnel as:

$$
\eta_{\mathrm{EE}}=\frac{\mathrm{PO}_{\mathrm{MHD}}}{\dot{\mathrm{m}}_{\mathrm{He}} \mathrm{C}_{\mathrm{p}} \mathrm{T}_{\mathrm{i}}}=\frac{\mathrm{K}(1-\mathrm{K}) \sigma \mathrm{u}^{2} \mathrm{~B}^{2} \mathrm{~V}}{\dot{\mathrm{m}}_{\mathrm{He}} \mathrm{C}_{\mathrm{p}} \mathrm{T}_{\mathrm{i}}}
$$

Where:

$$
\begin{aligned}
\mathrm{PO}_{\mathrm{MHD}}= & \text { Electrical Power } \\
\mathrm{V}= & \text { The Volume of } \mathrm{MHD} \text { power generation } \\
& \text { channel } \\
\dot{\mathrm{m}}_{\mathrm{He}}= & \text { The mass flow rate } \\
\mathrm{C}_{\mathrm{p}}= & \text { The heat capacity at a constant pressure } \\
\eta_{\mathrm{EE}}= & \text { Under the conditions discussed in this study } \\
& \text { the enthalpy extraction rate in Table } 2
\end{aligned}
$$

For the MHD duct, assumed to be an ideal continues faraday generator, considering a 1D approach, the governing equations of state can be written as:

$$
\mathrm{P}=\rho \mathrm{R}_{\mathrm{He}} \mathrm{T}
$$

where, $\mathrm{R}_{\mathrm{He}}$ is gas constant of Helium. The electrical efficiency of MHD generator is defined as (Aithal, 2009):

$$
\eta_{\mathrm{e}}=\frac{\mathrm{JE}}{\mathrm{VJB}}
$$

Equation 11 give a clear idea about the internal irreversibilities of the $\mathrm{MHD}$ generator.

Nozzle and diffuser: The nozzle and diffuser outlet pressure, temperature and density of the Mach subsonic flow between stagnation and static conditions can be calculated by Yiwen et al. (2011), Cicconardi and Perna (2014):

$$
\begin{gathered}
\frac{\mathrm{P}_{0}}{\mathrm{P}}=\left(1+\frac{\gamma-1}{2} \mathrm{Ma}^{2}\right)^{\gamma /(\gamma-1)} \\
\frac{\mathrm{T}_{0}}{\mathrm{~T}}=1+\frac{\gamma-1}{2} \mathrm{Ma}^{2} \\
\frac{\rho_{0}}{\rho}=\left(1+\frac{\gamma-1}{2} \mathrm{Ma}^{2}\right) \gamma /(\gamma-1)
\end{gathered}
$$

Where:

$$
\begin{array}{ll}
\mathrm{T}(\mathrm{K}) \text { and } \mathrm{P}(\mathrm{kPa})= & \text { The plasma temperature and } \\
& \text { pressure, respectively } \\
\gamma & \begin{array}{l}
\text { The ratio between specific heats } \\
\\
\end{array} \\
= & \text { at constant pressure and volume } \\
\mathrm{Ma} & \text { The Mach number of the plasma }
\end{array}
$$

Recuperator: The recuperator model is based on the definition of the effectiveness $\left(\mathrm{C}_{\text {cool }}=\mathrm{C}_{\min }\right)$ which is defined as (Klein and Alvarda, 2007; Spring, 1965):

$$
\varepsilon_{\text {rec }}=\frac{Q_{\text {Recup.act }}}{Q_{\text {Re cup.max }}}=\frac{C_{\text {cool }}\left(T_{c . e}-T_{c . i}\right)}{C_{\text {min }}\left(T_{h . i}-T_{c . i}\right)}
$$

The first law of thermodynamics $\left(\dot{\mathrm{m}}_{\mathrm{h}}=\dot{\mathrm{m}}_{\mathrm{c}}\right)$ in the recuperator can be formulated as:

$$
\dot{\mathrm{m}}_{\mathrm{h}}\left(\mathrm{C}_{\mathrm{p}}\right)_{\mathrm{h}}\left(\mathrm{T}_{\mathrm{h} . \mathrm{i}}-\mathrm{T}_{\mathrm{h} . \mathrm{e}}\right)=\dot{\mathrm{m}}_{\mathrm{c}}\left(\mathrm{C}_{\mathrm{p}}\right)_{\mathrm{C}}\left(\mathrm{T}_{\mathrm{c} . \mathrm{e}}-\mathrm{T}_{\mathrm{c} . \mathrm{i}}\right)
$$

Cooler: The cooler model is also based on the definition of the effectiveness $\left(\mathrm{C}_{\text {hot }}=\mathrm{C}_{\min }\right)$ which is defined as (Klein and Alvarda, 2007):

$$
\varepsilon_{C}=\frac{Q_{\text {C.act }}}{Q_{\text {C.max }}}=\frac{C_{\text {hot }}\left(T_{\text {h.i }}-T_{\text {h.e }}\right)}{C_{\text {min }}\left(T_{\text {h.i }}-T_{c . i}\right)}
$$

The energy balances can be expressed as:

$$
\dot{\mathrm{m}}_{\mathrm{h}}\left(\mathrm{h}_{\mathrm{h} . \mathrm{i}}-\mathrm{h}_{\mathrm{h} . \mathrm{e}}\right)=\dot{\mathrm{m}}_{\mathrm{c}}\left(\mathrm{h}_{\mathrm{c} . \mathrm{e}}-\mathrm{h}_{\mathrm{c} . \mathrm{i}}\right)
$$

Intercooler: The intercooler can also be modeled utilizing definition of the effectiveness $\left(\mathrm{C}_{\text {hot }}=\mathrm{C}_{\text {min }}\right)$ as (Klein and Alvarda, 2007):

$$
\varepsilon_{\text {IC }}=\frac{Q_{\text {IC.act }}}{Q_{\text {IC } \max }}=\frac{C_{\text {hot }}\left(T_{\text {h.i }}-T_{\text {h.e }}\right)}{C_{\text {min }}\left(T_{\text {c.e }}-T_{c . i}\right)}
$$

The energy and exergy balances can be expressed as follows:

$$
\dot{\mathrm{m}}_{\mathrm{h}}\left(\mathrm{C}_{\mathrm{p}}\right)_{\mathrm{h}}\left(\mathrm{T}_{\mathrm{h} . \mathrm{i}}-\mathrm{T}_{\mathrm{h} . \mathrm{e}}\right)=\dot{\mathrm{m}}_{\mathrm{c}}\left(\mathrm{C}_{\mathrm{p}}\right)_{\mathrm{C}}\left(\mathrm{T}_{\mathrm{c} . \mathrm{e}}-\mathrm{T}_{\mathrm{c} . \mathrm{i}}\right)
$$

For the overall CCPP, the performance in terms of the energy efficiencies for the MHD cycle and overall plant (CCPP), respectively are evaluated as follows (Yari and Mahmoudi, 2010):

$$
\begin{gathered}
\eta_{\text {I.MHD }}=\frac{\dot{\mathrm{W}}_{\mathrm{MHD}}-\dot{\mathrm{W}}_{\text {Comp }}}{\dot{\mathrm{Q}}_{\text {in.CCPP }}} \\
\eta_{\text {I.CCPP }}=\frac{\dot{\mathrm{W}}_{\text {net.MHD }}}{\dot{\mathrm{Q}}_{\text {in.CCPP }}}
\end{gathered}
$$

The above equations were numerically solved and the temperature and enthalpy of each flow of the plant determined.

Exergy analysis: Exergy can be divided into four components: physical, chemical, kinetic and potential. The latter two assumed negligible in this study, since, changes 
in elevation and speed (except $\mathrm{MHD}$ generation) are small (Spring, 1965; Kanoglu et al., 2007). Physical exergy is defined as the maximum theoretical useful work obtained as a system interacts with a reference environment at an equilibrium state (Yari and Mahmoudi, 2010). Chemical exergy is associated with the departure of the chemical composition of a system from the chemical composition of the reference environment. Chemical exergy is significant for fuels. Applying the first and second laws of thermodynamics an exergy balance can be obtained:

$$
\dot{\mathrm{E}} \mathrm{x}_{\mathrm{Q}}+\sum_{\mathrm{i}} \dot{\mathrm{E}} \mathrm{x}_{\mathrm{i}}=\dot{\mathrm{E}} \mathrm{x}_{\mathrm{w}}+\sum_{\mathrm{e}} \dot{\mathrm{E}} \mathrm{x}_{\mathrm{e}}+\dot{\mathrm{I}}_{\text {destruction }}
$$

Where:

$\mathrm{Ex} \quad=$ Exergy rate and subscripts

$\mathrm{i}$ and $\mathrm{e}=$ The inlet and outlet of a control volume

$\dot{\mathrm{I}}_{\text {destruction }}=$ The exergy destruction

And other terms are as follows (Yari and Mahmoudi, 2010; Dincer and Cengel, 2001; Ahmadi, 2006):

$$
\begin{aligned}
& \dot{\mathrm{Ex}}_{\mathrm{Q}}=\int_{\mathrm{i}}^{\mathrm{f}}\left(1-\mathrm{T}_{0} / \mathrm{T}\right) \delta \mathrm{Q}=\left(1-\frac{\mathrm{T}_{0}}{\mathrm{~T}_{\mathrm{i}}}\right) \dot{\mathrm{Q}}_{\mathrm{i}} \\
& \dot{\mathrm{Ex}}_{\mathrm{w}}=\dot{\mathrm{W}}_{\mathrm{ex}} \\
& \mathrm{ex}=\mathrm{ex}_{\mathrm{ph}}+\mathrm{ex}_{\mathrm{ch}}+\mathrm{ex}_{\mathrm{kin}}+\mathrm{ex}_{\mathrm{pot}} \\
& \mathrm{ex}_{\mathrm{ph}}=\left(\mathrm{h}-\mathrm{h}_{0}\right)-\mathrm{T}_{0}\left(\mathrm{~s}-\mathrm{s}_{0}\right) \\
& \mathrm{ex}_{\mathrm{ch}}=\sum_{\mathrm{i}=1} \mathrm{x}_{\mathrm{i}} \mathrm{ex}_{\mathrm{ch}}+\mathrm{RT}_{0} \sum_{\mathrm{i}=1} \mathrm{x}_{\mathrm{i}} \text { In } \mathrm{x}_{\mathrm{i}} \\
& \mathrm{ex}_{\mathrm{kin}}=\frac{\mathrm{u}^{2}}{2} \text { (only for MHD generation) } \\
& \mathrm{ex}_{\mathrm{pot}}=\mathrm{ex}_{\mathrm{kin}}=0
\end{aligned}
$$

Here $\dot{\mathrm{E}} \mathrm{x}_{\mathrm{Q}}$ and $\dot{\mathrm{E}} \mathrm{x}_{w}$, respectively are the corresponding exergy rates associated with heat transfer and research across the boundary of a control volume, $\mathrm{ex}_{\mathrm{ph}} \mathrm{ex}_{\mathrm{ch}} \mathrm{ex}_{\mathrm{knn}}$ and $\mathrm{ex}_{\mathrm{pot}}$, respectively are physical, chemical, kinetic and potential exergy, $\mathrm{T}$ is the absolute temperature and the subscript of refers to the reference environment conditions. The reference environment considered in our study is $\mathrm{P}_{0}=100 \mathrm{kPa}$ and $\mathrm{T}_{0}=298.15 \mathrm{~K}$.

In the present research, the exergy of each flow is evaluated and the changes in the exergy are determined for each major component.
The exergy destruction rate and the exergy efficiency for each component and for the overall power plant (Fig. 1 and 2) are shown in Table 1. The source of exergy destruction (or irreversibility) in the NFR is mainly heat transfer across large temperature differences between fuel rod and helium flow while exergy destruction in the primary system heat exchanger (the HRVG) is due to the temperature differences between the hot and cold fluids. Similar results were obtained by Ameri and Ahmadi (2007), Ameri et al. (2008) and Hamidi (2006):

$$
\eta_{\mathrm{II}}=\frac{\stackrel{\mathrm{W}}{\mathrm{W}}_{\mathrm{net}}}{\mathrm{E} \mathrm{x}_{\mathrm{i} \text {.cycle }}}
$$

Where:

$$
\begin{aligned}
\eta_{\mathrm{II}}, \dot{\mathrm{w}}_{\text {ret }} \text { and } \dot{\mathrm{Ex}}_{\mathrm{x}_{\text {icyle }}=}= & \text { The second law efficiency } \\
\mathrm{CCPP} & \text { Net output electrical power and } \\
& \text { total input exergy rate of MHD } \\
& \text { cycle }
\end{aligned}
$$

The total exergy destruction rate in the cycle is as follows:

$$
\dot{\mathrm{I}}_{\text {Dest }}=\dot{\mathrm{I}}_{\text {Dest.MHD }}
$$

In addition, the component exergy destruction ratio, $\mathrm{Y}_{\mathrm{D}, \mathrm{i}}$ which provides more information about the weak points of the cycle from the view point of second law of thermodynamics (Mgbachi, 2015) is employed:

$$
\begin{aligned}
& \stackrel{\square}{\mathrm{Y}}_{\text {D. } \mathrm{i}}=\frac{\stackrel{\mathrm{I}}{\text { Dest.i }}^{\mathrm{a}}}{\mathrm{E} \mathrm{x}_{\text {i.cyde }}} \\
& \stackrel{\square}{\mathrm{E}} \mathrm{x}_{\text {i.cycle }}=\stackrel{\mathrm{Q}}{\mathrm{W}}_{\text {net }}+\stackrel{\mathrm{q}}{\mathrm{I}}_{\text {Dest }}
\end{aligned}
$$

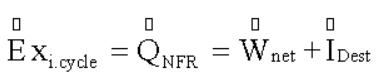

\section{MATERIALS AND METHODS}

Model validation: In order to validate the simulation results the available data in literature were used. For the case of the CCMHD, the thermodynamic model was validated using the previously published data (Litchford and Harada, 2011). They were examined assuming closed cycle coupling of a high-temperature Fission Reactor (NFR) with Magneto Hydro Dynamic (MHD) energy conversion and utilization of a nonequilibrium helium/xenon Frozen Inert Plasma (FIP). 
The helium/xenon working fluid and the number of compressor compression stages were 1-6 which ultimately provided the best efficiency for the 3rd step of compression and $55.2 \%$. The baseline performance characteristics of the CCMHD are given in Table 2 .

\section{RESULTS AND DISCUSSION}

In the present research, exactly the same characteristics were modeled using a computer program. The results of this study are entirely consistent with the results reported by Litchford and Harada (2011) as shown in Fig. 3. In a study by Litchford and Harada (2011) a disk MHD generator was used to compare these generators with the Faraday MHD generator from the relationships provided by the researchers (Yiwen et al., 2011; Sun et al., 2017 and Rosa, 1987).

After thermodynamic modeling of the Faraday generator, the MHD cycle with the same process specification showed a significant loss in cycle efficiency, the results of which are shown in Fig. 4. As can be seen from the results, the efficiency of the cycle has been greatly reduced due to the fact that the pressure drop is almost two times higher in the Faraday generator than the disc generator which has led to a significant increase in the power consumption of the compressors. In this case, the best efficiency for a 5 -stage compressor is $40.36 \%$.

Figure 5 shows the effect of recuperator efficiency changes on total cycle efficiency. When recuperator efficiency is decreased, i.e., regenerated heat is reduced; Thermal input to the NFR is also decreased as the temperature output from the NFR is kept the same level of $1800 \mathrm{~K}$. Thus increased input thermal power of the NFR, results in the decrease of total first law efficiency. If the recuperator is removed from the system, first law efficiency decreases about $28 \%$. Figure 6 for instance, shows radiated waste heat, $Q_{T}=Q_{C}+Q_{I C}$ and total first law efficiency versus cooler temperature. For space applications (Litchford and Harada, 2011), waste heat must be entirely rejected via. the radiative driving potential which forces the cooler size and mass to increase rapidly as heat rejection temperature falls. Because the cooler temperature represents the bottoming temperature of the cycle, however, first law efficiency must fall dramatically as temperature rises. In this particular case for instance, net electrical output power approaches zero when the radiative cooler temperature reaches $800 \mathrm{~K}$. Because the radiated power exhibits a strong fourth-power dependence on radiator (cooler) temperature, high efficiency low temperature operating characteristics require exceedingly large radiatorsizes and

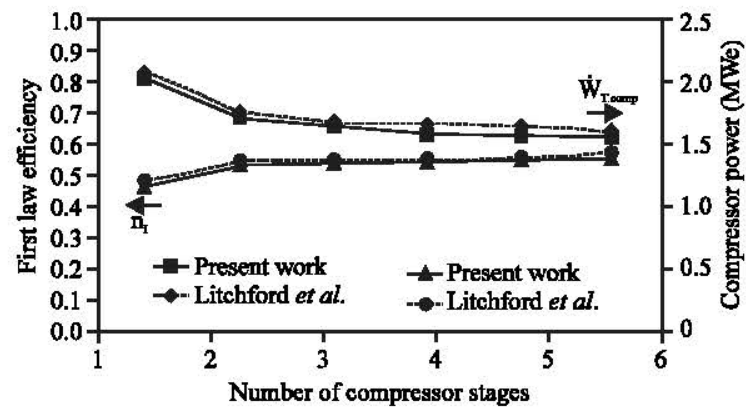

Fig. 3: Verification of compressor stage number on first law efficiency and compressor power in the present work with the previously published data

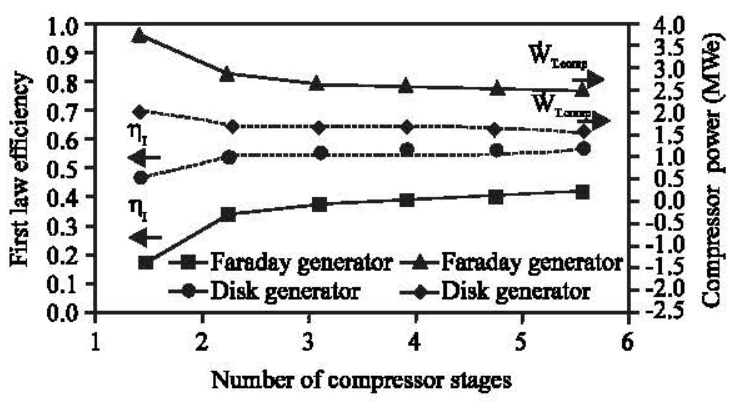

Fig. 4: Verification of compressor stage number on first law efficiency and compressor power in the Faraday and disk generator

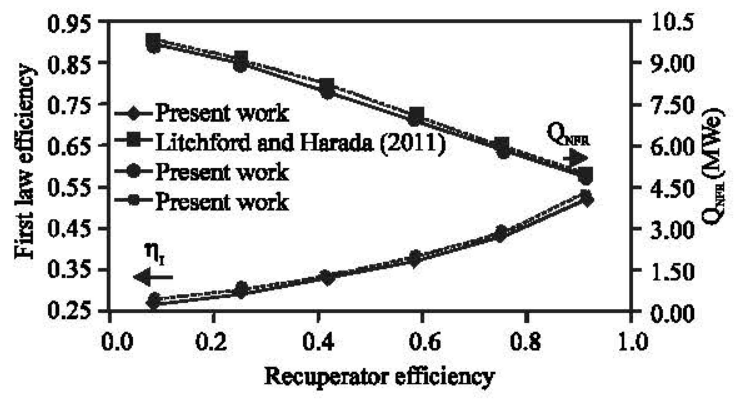

Fig. 5: Verification of recuperator efficiency effects on first law efficiency and NFR power in the present work with the previously published data

mass. Thus, clarification of an optimal design strategy again requires careful analysis of system specific mass attributes. In the present research, Table 3 list the values of temperature, pressure, mass flow rate and exergy rate calculated in the closed-MHD cycles with Faraday generator according to the cnomenclature shown in Fig. 1. The results from first-law analysis for a typical cycle component at the case conditions are presented in Table 4. A parametric study is conducted to examine 
Table 3: Calculated thermodynamic properties of working fluids in CCMHD power plant ( $\mathrm{T} 3=1800 \mathrm{~K}, \mathrm{TC}=298 \mathrm{~K}$, $\mathrm{SOC}=5$ )

\begin{tabular}{|c|c|c|c|c|c|c|c|}
\hline State No & Fluid & Pressure $\mathrm{P}(\mathrm{kPa})$ & Temperature $\mathrm{T}(\mathrm{K})$ & Mass flow rate $\mathrm{m} /(\mathrm{kg} / \mathrm{sec})$ & Enthalpy $\mathrm{h}(\mathrm{kJ} / \mathrm{kg})$ & Entropy s (kJ/kg K) & Exergy rate $\mathrm{E}_{\mathrm{i}}(\mathrm{kW})$ \\
\hline 1 & Helium & 414 & 368.2 & 78.71 & 365.3 & -1.827 & 72224 \\
\hline 2 & Helium & 409.9 & 1130 & 78.71 & 4320 & 4.016 & 246432 \\
\hline 3 & Helium & 399.6 & 1800 & 78.71 & 7799 & 6.487 & 462382 \\
\hline 4 & Helium & 371.1 & 1748 & 78.71 & 7527 & 6.487 & 462376 \\
\hline 5 & Helium & 43.09 & 1136 & 78.71 & 4351 & 8.722 & 159925 \\
\hline 6 & Helium & 46.4 & 1170 & 78.71 & 4528 & 8.722 & 152427 \\
\hline 7 & Helium & 45.93 & 408.3 & 78.71 & 572.3 & 3.276 & 31175 \\
\hline 8 & Helium & 45.47 & 300 & 78.71 & 9.754 & 1.696 & 38406 \\
\hline 9 & Helium & 70.73 & 368.2 & 78.71 & 364.2 & 1.843 & 13949 \\
\hline 10 & Helium & 70.73 & 300 & 78.71 & 9.836 & 0.7789 & 16877 \\
\hline 11 & Helium & 110 & 368.2 & 78.71 & 364.3 & 0.9256 & 7584 \\
\hline 12 & Helium & 110 & 300 & 78.71 & 9.963 & -0.1387 & 4656 \\
\hline 13 & Helium & 171.1 & 368.2 & 78.71 & 364.5 & 0.008042 & 29122 \\
\hline 14 & Helium & 171.1 & 300 & 78.71 & 10.16 & -1.056 & 26193 \\
\hline 15 & Helium & 266.2 & 368.2 & 78.71 & 364.8 & -0.9095 & 50667 \\
\hline 16 & Helium & 266.2 & 300 & 78.71 & 10.47 & -1.974 & 47739 \\
\hline 17 & Water & 100 & 298 & 1006 & 104.2 & 0.3648 & 0 \\
\hline 18 & Water & 100 & 308 & 1006 & 146 & 0.5029 & 690.4 \\
\hline 19 & Water & 100 & 298 & 2534 & 104.2 & 0.3648 & 0 \\
\hline 20 & Water & 100 & 308 & 2534 & 146 & 0.5029 & 1740 \\
\hline 21 & Water & 100 & 298 & 2534 & 104.2 & 0.3648 & 0 \\
\hline 22 & Water & 100 & 308 & 2534 & 146 & 0.5029 & 1740 \\
\hline 23 & Water & 100 & 298 & 2534 & 104.2 & 0.3648 & 0 \\
\hline 24 & Water & 100 & 308 & 2534 & 146 & 0.5029 & 1740 \\
\hline 25 & Water & 100 & 298 & 2534 & 104.2 & 0.3648 & 0 \\
\hline 26 & Water & 100 & 308 & 2534 & 146 & 0.5029 & 1740 \\
\hline
\end{tabular}

Table 4: Energy flow of MHD cycle components ${ }^{a}$

\begin{tabular}{ll}
\hline Variables & CCMHD \\
\hline Component & Energy flow (kW) \\
Compressor & 139460 \\
NFR & 273905 \\
MHD duct & 250014 \\
Cooler & 44279 \\
Intercooler & 111568 \\
\hline T $3=1800 \mathrm{k} \mathrm{TC}=300 \mathrm{~K} \mathrm{SOC}=5 \mathrm{EE}=35 \%$ &
\end{tabular}

the effects on the power plant performance of key operating parameters of both MHD and power cycle sub-systems. The most important parameter affecting the system performance in terms of efficiency and output power is number of compression stages (1-7 stages).

Figure 7 shows net output power, first and second law efficiency against number of compressor stages. It can be seen that plant efficiency increases with the increase of compressor stage number owing to increase number of intercoolers which can reduce power worked by the working gas. We have to note, however, this effect is not significant at the number in excess of 5 . So, we choosed 5 compression stages for show results.

Figure 8 shows the first and second law efficiency versus outlet temperature of NFR for gas Temperature $\left(\mathrm{T}_{3}\right)$ of $1600-2300 \mathrm{~K}$. As we can see from this figure that when outlet temperature of NFR is increased, shows the first and second law efficiency are increased. In this

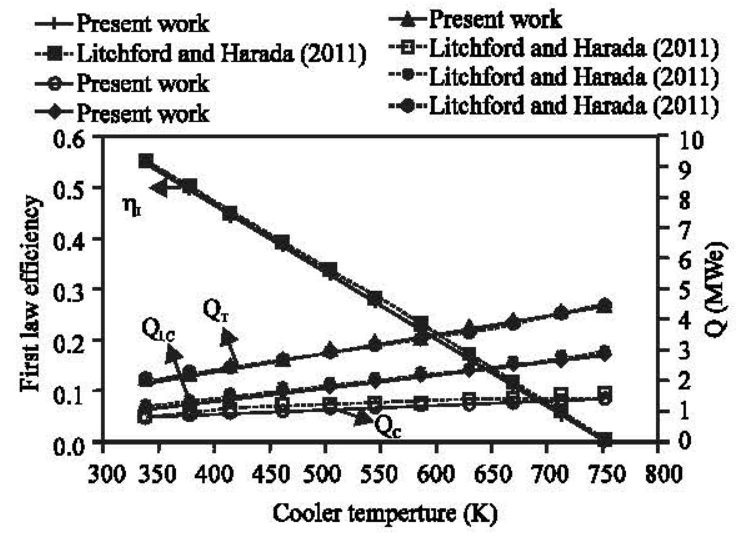

Fig. 6: Verification of cooler temperature effects on first law efficiency in the present work with the previously published data

system, the first and second law efficiency are $51.13 \%$ at the highest value when NFR output temperature is $2300 \mathrm{k}$.

Figure 9 shows the variations of power plant energy efficiencies with the helium outlet temperature of $\mathrm{NFR}\left(\mathrm{T}_{3}\right)$ is $2000 \mathrm{~K}-2300 \mathrm{~K}$ with the enthalpy extraction of MHD generator of $35-40 \%$.

When output temperature is $2300 \mathrm{~K}$, the total plant efficiency is highest as $51.13 \%$ shown in Fig. 9. When output temperature increased more the efficiency decreased. This reason because when enthalpy extraction increased, more power is supplied back to compressor. 


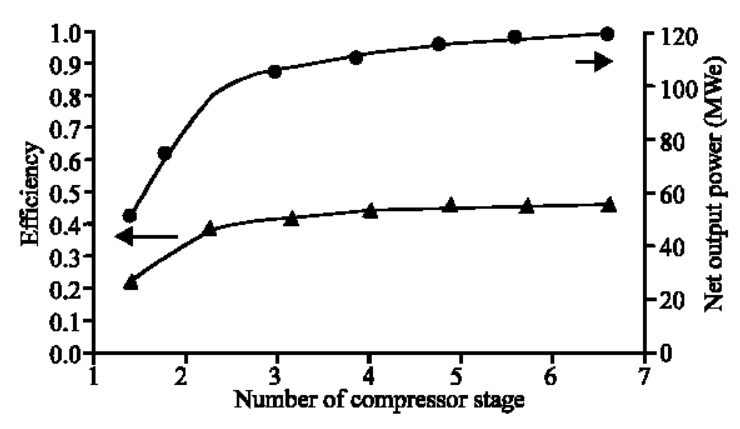

Fig. 7: Verification of compressor stage number on net output power and first and second law efficiency



Fig. 8: Verification of outlet temperature of NFR on the first and second law efficiency

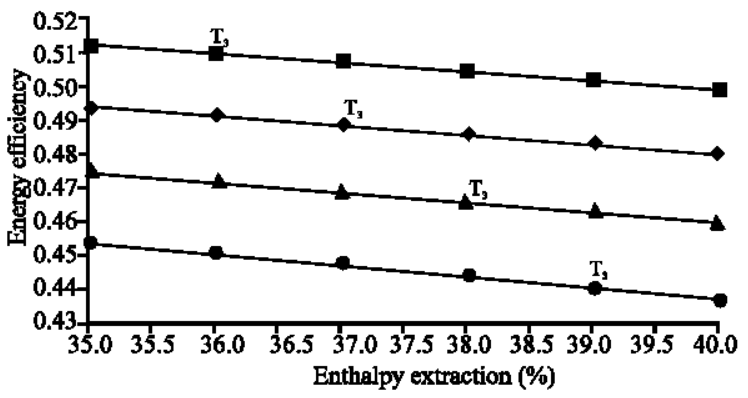

Fig. 9: Verification of enthalpy extraction on the first law efficiency with the helium outlet temperature of NFR

Figure 10 shows maximum amount enthalpy extraction for maximum first-law efficiency versus outlet temperature of NFR for gas Temperature $\left(\mathrm{T}_{3}\right)$ from $1600-2300 \mathrm{~K}$. When output temperature and enthalpy extraction increased more the efficiency increased. As we can see from this figure that when $\mathrm{T}_{3}=2300 \mathrm{~K}$ and enthalpy extraction is $34.79 \%$, maximum amount first-law efficiency is $51.17 \%$.

Figure 11 shows the effect of mass flow and the output power of the MHD channel changes versus outlet

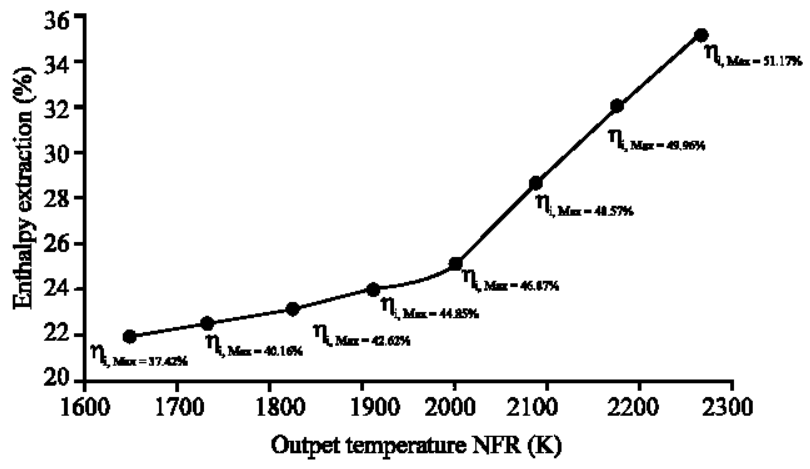

Fig. 10: Verification of outlet temperature of NFR on the first law efficiency

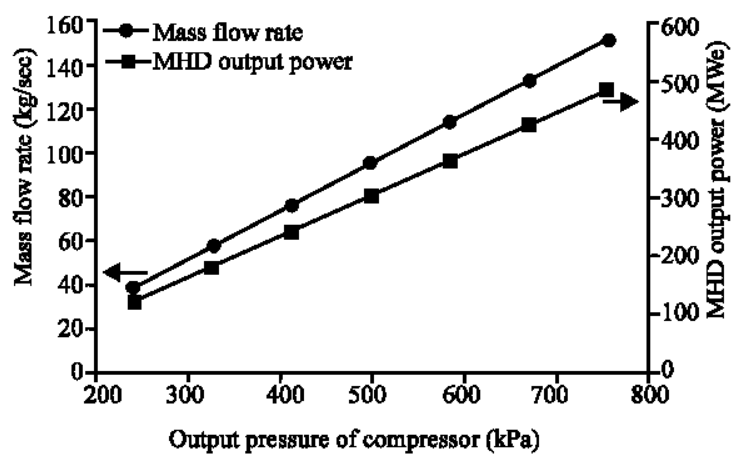

Fig. 11: Verification of outlet pressure of compressor on the mass flow and output power of the MHD channel

pressure of compressor $\left(\mathrm{P}_{1}\right)$. As the output pressure is increased from $200-800 \mathrm{kPa}$, the flow rate ranges from $38.03-152.1 \mathrm{~kg} / \mathrm{sec}$ and the output power is $120.78-483.2$ MW due to the increase in the channel dimensions and the difference in inlet and outlet pressure MHD has risen. Also, the intensity of the fluctuation in the mass flow rate of the operating fluid is greater than the intensity of the variation in the $\mathrm{MHD}$.

Figure 12 show compressor research, first and second law efficiency versus outlet temperature of cooler. It can be seen that plant efficiency decreases with the increase of outlet temperature which is due to the increase in the compressor work. Because at a fixed rate of mass of helium, the density decreases with increasing temperature, therefore, the compressor's work increases because of the increase in the compression ratio thus the net power of the cycle decreases, so that, at $540 \mathrm{~K}$, the cycle efficiency will be zero.

Figure 13 shows the effect of changes in mass flow rate, the first and second law efficiency of the power plant compared to the extraction enthalpy. It seems that the flow rate of working fluid from $\mathrm{MHD}$ duct has increased 
in response to the increase in the extraction enthalpy due to the increase in the difference in the temperature and pressure of the inlet and outlet of the duct, therefore, the first and second law efficiency of the MHD single power generation cycle is reduced. In the study, the highest efficiency of the first and second law according to the working conditions in the enthalpy of extraction is $23.16 \%$ which is $42.62 \%$ in NFR outlet temperature $1800 \mathrm{~K}$.

Figure 14 depicts the exergy destruction ratio in each component of the CCMHD. In fact, this figure shows that, how much each component contributes to the total irreversibility of the plant. The exergy analysis

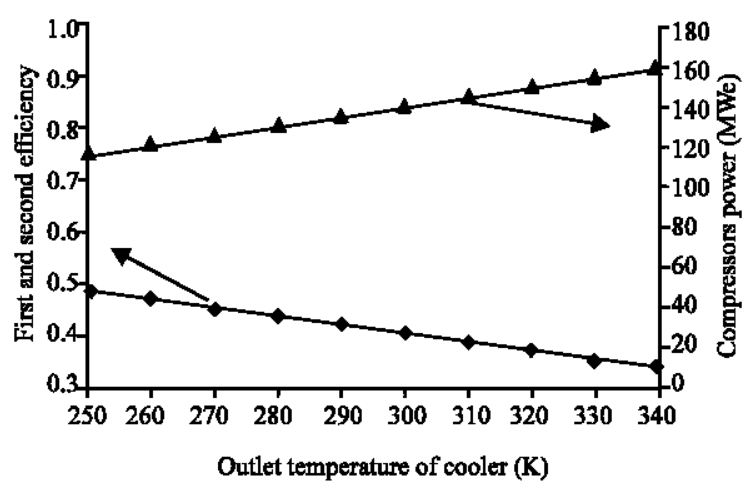

Fig. 12: Verification of outlet temperature of cooler on the compressors power, first and second law efficiency

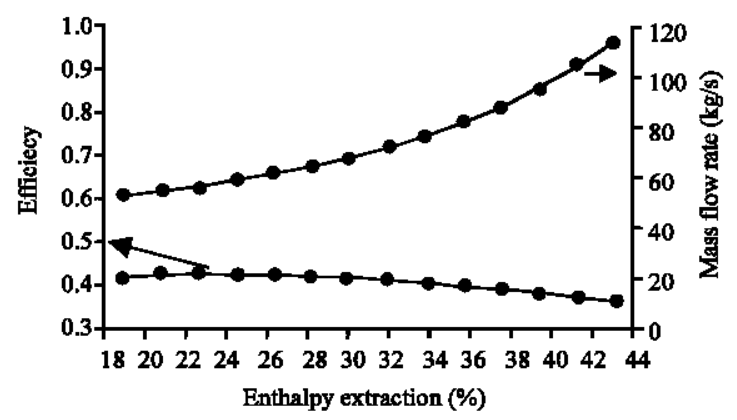

Fig. 13: Verification of enthalpy extraction on the mass flow, first and second law efficiency of each system is based on the operating conditions shown in Table 2 and 3 . The maximum exergy destruction ratio is related to the $\mathrm{MHD}$ generator in base cycles. For the CCMHD cycle, the next-largest exergy destruction occurs in the NFR, compressors, intercooler, recuperator and cooler, respectively. Paying more attention to the exergy destruction ratio diagram presented in Fig. 14 shows that about 59.4\% of the exergy entering the plant is lost in CCMHD cycles.

As NFR outlet temperature increases the first and second law efficiencies and power generation grows up. This can be explained with the help of $\eta_{\mathrm{I} \text { ICPP }}=1 \overline{\mathrm{T}}_{\mathrm{L}} / \overline{\mathrm{T}}_{\mathrm{H}}=\dot{\mathrm{W}}_{\mathrm{rtt}} / \dot{\mathrm{Q}}_{\mathrm{inccpp}}$. In addition with increasing NFR outlet temperature, the exergy destruction rate decreased. This can be explained through the following equation $\left(\dot{\mathrm{E}}_{\mathrm{xin}}=\stackrel{\mathrm{Q}}{\mathrm{urn}}_{\mathrm{g}}\right)$ :

In fact, $\dot{\mathrm{W}}_{\mathrm{nt}}$ increases, bringing about a decrease of $\dot{\mathrm{I}}_{\text {Dest }}$ Table 5 also indicates that the helium mass flow rate decreases with increasing $\mathrm{T}_{3}$. Equation $\dot{\mathrm{Q}}_{\mathrm{in}}=\dot{\mathrm{m}}_{\mathrm{He}}(\Delta \mathrm{h})$ explains this variations: As $\mathrm{T}_{3}$ increases the enthalpy change $(\Delta \mathrm{h})$ of helium through the NFR increases which causes a decrease in the helium mass flow rate through the CCMHD cycle.

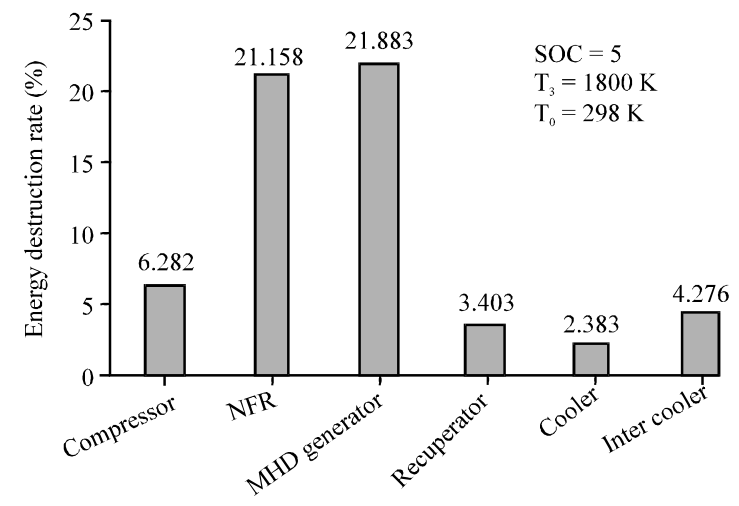

Fig. 14: The rate of exergy destructions in the components of CCMHD power plant in comparison to the input exergy

Table 5: Summary of results for maximum first-law efficiency of the MHD cycle (SOC $=5$ )

\begin{tabular}{|c|c|c|c|c|c|c|c|c|}
\hline $\begin{array}{l}\text { Optimum design/ } \\
\text { operating parameters }\end{array}$ & 1600 & 1700 & 1800 & 1900 & 2000 & 2100 & 2200 & 2300 \\
\hline$\overline{\eta_{I}(\%)}$ & 34.110 & 37.430 & 40.360 & 42.980 & 45.330 & 47.450 & 49.370 & 51.130 \\
\hline$\eta_{\text {II }}(\%)$ & 34.110 & 37.430 & 40.360 & 42.980 & 45.330 & 47.450 & 49.370 & 51.130 \\
\hline$\dot{\mathrm{W}}_{\text {net }}(\mathrm{MW})$ & 87.796 & 99.467 & 110.554 & 121.124 & 131.234 & 140.931 & 150.255 & 159.239 \\
\hline$\dot{\mathrm{m}}_{\mathrm{He}}(\mathrm{kg} / \mathrm{sec})$ & 83.490 & 81.000 & 78.710 & 76.610 & 74.670 & 72.870 & 71.200 & 69.630 \\
\hline I. (MW) & 168.870 & 165.603 & 162.662 & 160.002 & 157.587 & 155.386 & 153.373 & 151.528 \\
\hline
\end{tabular}




\section{CONCLUSION}

In this study, an integrated CCMHD plant was analyzed. A thermodynamic model has been developed by applying the first and the second laws for each system component and regarding the first and second law efficiency and calculation was performed using the computer programming. The model was verified through a comparison between results of the current model and those available in the literature for similar operating conditions. The results obtained indicate that the first law efficiencies and power generation of the CCMHD plant is increased with increasing NFR inlet temperature.

The results of the analysis show that the maximum efficiency of the first and second law of the cycle at a nominal load of $250 \mathrm{MW}$ with a temperature output of NFR at $2300 \mathrm{~K}$ and enthalpy extraction $34.79 \%$ using a faraday $\mathrm{MHD}$ generator are $51.17 \%$. Paying more attention to the exergy destruction is reduced with increasing NFR outlet temperature from 168-151 kW. The MHD generatorin this case is the most important cause of exergy destruction of cycle about $20 \%$.

\section{REFERENCES}

Ahmadi, P., 2006. Exergy concepts and exergy analysis of combined cycle power plants: A case study in Iran. BSc Thesis, Energy Engineering Department, Power and Water University of Technology (PWUT), Tehran, Iran.

Aiboud, S. and S. Saouli, 2010. Entropy analysis for viscoelastic magnetohydrodynamic flow over a stretching surface. Int. J. Non-Linear Mech., 45: 482-489.

Aithal, S.M., 2009. Characteristics of optimum power extraction in a MHD generator with subsonic and supersonic inlets. Energy Convers. Manage., 50: 765-771.

Ameri, M. and P. Ahmadi, 2007. The Study of Ambient Temperature Effects on Exergy Losses of a Heat Recovery Steam Generator. In: Challenges of Power Engineering and Environment, Cen, K., Y. Chi and F. Wang (Eds.). Springer, Berlin, Germany, ISBN:978-3-540-76693-3, pp: 55-60.

Ameri, M., P.O.U.R.I.A. Ahmadi and S.H.O.A.I.B. Khanmohammadi, 2008. Exergy analysis of a $420 \mathrm{MW}$ combined cycle power plant. Intl. J. Energy Res., 32: 175-183.

Aoki, L.P., M.G. Maunsell and H.E. Schulz, 2012. A magnetohydrodynamics study of behavior in an electrolyte fluid using numerical and experimental solutions. Therm. Eng., 11: 53-60.
Ayeleso, A.O. and M.T. Kahn, 2017. Modelling of a combustible ionised gas in thermal power plants using MHD conversion system in South Africa. J. King Saud Univ. Sci., 1: 1-8.

Ayeleso, A.O., M.T.E. Kahn and A.K. Raji, 2015. Plasma energy conversion system for electric power generation. Proceedings of the International Conference on Industrial and Commercial use of Energy (ICUE'15), August 18-19, 2015, IEEE, Cape Town, South Africa, ISBN:978-1-4673-9370-6, pp: 206211.

Bejan, A., G. Tsatsaronis and M. Moran, 1996. Thermal Design and Optimization. John Wiley and Sons, New York, USA.

Benyo, T., 2010. The effect of MHD energy bypass on specific thrust for supersonic turbojet engine. Proceedings of the 48th AIAA Conference on Aerospace Sciences Meeting Including the New Horizons Forum and Aerospace Exposition, January 4-7, 2010, Orlando, Florida, USA., ISBN:9781617384226, pp: 1-15.

Bityurin, V.A., J. Lineberry, R. Litchford and J. Cole, 2000. Thermodynamic analysis of the AJAX propulsion concept. Proceedings of the 38th AIAA Conference on Aerospace Sciences Meeting and Exhibit, January 10-13, 2000, The American Institute of Aeronautics and Astronautics, Reno, Nevada, pp: 445-445.

Chandra, A. and G.K. Pandey, 2005. Conceptual design and application of liquid metal MHD system for hydrogen production. Proceedings of the 15th Riga and 6th PAMIR Conference on Fundamental and Applied MHD Liquid Metal Technologies, June 27July 1, 2005, Riga Publisher, Jurmala, Latvia, pp: 295298.

Chen, L., J. Gong, F. Sun and C. Wu, 2002. Heat transfer effect on the performance of $\mathrm{MHD}$ power plant. Energy Convers. Manage., 43: 2085-2095.

Cicconardi, S.P. and A. Perna, 2014. Performance analysis of integrated systems based on MHD generators. Energy Procedia, 45: 1305-1314.

Dincer, I. and M.A. Rosen, 2007. Exergy: Energy, Environment and Sustainable Development. Elsevier Science, London, UK., ISBN-13: 9780080531359 , Pages: 472.

Dincer, I. and Y.A. Cengel, 2001. Energy, entropy and exergy concepts and their roles in thermal engineering. Entropy, 3: 116-149.

Ebadi, M.J. and M. Gorji-Bandpy, 2005. Exergetic analysis of gas turbine plants. Int. J. Exergy, 2: 31-39.

Hamidi, A., 2006. Exergy and exergoeconomic analysis of steam power plant: A case study in Iran. BSc Thesis, Energy Engineering Department, Power and Water University of Technology (PWUT), Tehran, Iran. 
Ibanez, G., S. Cuevas and M.L.D. Haro, 2002. Optimization analysis of an alternate magnetohydrodynamic generator. Energy Convers. Manage., 43: 1757-1771.

Ju, C.X., Y.C. Lu and B.H. Jing, 1998. Open Cycle MHD Power Generation. Beijing Industry University Press, Beijing, China, (In Chinese).

Kaminaga, S., S. Tomioka and H. Yamasaki, 2005. Feasibility study on MHD energy bypass scramjet engine. Proceedings of the AIAA/CIRA 13th International Conference on Space Planes and Hypersonics Systems and Technologies, May 16-20, 2005, AIAA, Capua, Italy, pp: 682-704.

Kanoglu, M., I. Dincer and M.A. Rosen, 2007. Understanding energy and exergy efficiencies for improved energy management in power plants. Energy Policy, 35: 3967-3978.

Kaushik, S.C., S.S. Verma and A. Chandra, 1995. Solarassisted liquid metal MHD power generation: A state of the art study. Heat Recovery Syst. CHP., 15: 675689.

Kayukawa, N., 2004. Open-cycle magneto hydro dynamic electrical power generation: A review and future perspectives. Prog. Energy Combust. Sci., 30: 33-60.

Klein, S.A. and S.F. Alvarda, 2007. Engineering Equation Solver (EES). F-Chart Software LLC, Madison, Wisconsin,.

Kotas, T.J., 1985. The Exergy Method of Thermal Plant Analysis. Butterworths, USA., ISBN: 9780408013505 , Pages: 296.

Litchford, R.J. and N. Harada, 2011. Multi-MW closed cycle $\mathrm{MHD}$ nuclear space power via nonequilibrium $\mathrm{He} / \mathrm{Xe}$ working plasma. Proceedings of the Conference on Nuclear and Emerging Technologies for Space, February 7-11, 2011, Albuquerque, New Mexico, pp: 1-9.

Mahian, O., S. Mahmud and I. Pop, 2012. Analysis of first and second laws of thermodynamics between two isothermal cylinders with relative rotation in the presence of MHD flow. Intl. J. Heat Mass Transfer, 55: 4808-4816.

Malghan, V.R., 1996. History of MHD power plant development. Energy Convers. Manage., 37: 569-590.

Masood, B., M.H. Riaz and M. Yasir, 2014. Integration of magnetohydrodynamics (MHD) power generating technology with thermal power plants for efficiency I mprovement. World Appl. Sci. J., 32: 1356-1363.

Mgbachi, C.A., 2015. Design analysis of Magnetohydrodynamic (MHD) electrical power generation technology. Intl. J. Adv. Res. Technol., 4: 103-108.
Mohagheghi, M. and J. Shayegan, 2009. Thermodynamic optimization of design variables and heat exchangers layout in HRSGs for CCGT, using genetic algorithm. Appl. Therm. Eng., 29: 290-299.

Mozafari, A., A. Ahmadi and M.A. Ehyaei, 2009. Optimisation of micro gas turbine by exergy, economic and environmental (3E) analysis. Intl. J. Exergy, 7: 1-19.

Rashidi, M.M., M. Ali, N. Freidoonimehr and F. Nazari, 2013. Parametric analysis and optimization of entropy generation in unsteady $\mathrm{MHD}$ flow over a stretching rotating disk using artificial neural network and particle swarm optimization algorithm. Energy, 55: 497-510.

Rashidi, M.M., O.A. Beg, A.B. Parsa and F. Nazari, 2011. Analysis and optimization of a transcritical power cycle with regenerator using artificial neural networks and genetic algorithms. Proc. Inst. Mech. Eng. Part A: J. Power Energy, 225: 701-717.

Rosa, R.J., 1987. Magnetohydrodynamic Energy Conversion. Hemisphere Publishing, New York, USA., .

Salas, H., S. Cuevas and M.L.D. Haro, 1999. Entropy generation analysis of magneto hydro dynamic induction devices. J. Phys. D. Appl., 32: 2605-2608.

Smrekar, J., M. Assadi, M. Fast, I. Kustrin and S. De, 2009. Development of artificial neural network model for a coal-fired boiler using real plant data. Energy, 34: 144152.

Spring, K.H., 1965. Direct Generation of Electricity. Academic Press, New York, USA., Pages: 410.

Sun, W., X. Yue and Y. Wang, 2017. Exergy efficiency analysis of ORC (Organic Rankine Cycle) and ORCbased combined cycles driven by low-temperature waste heat. Energy Convers. Manage., 135: 63-73.

Vishal, D.D. and S. Anand, 2013. The future power generation with $\mathrm{MHD}$ generators magneto hydrodynamics generation. Intl. J. Adv. Electr. Electron. Eng, 2: 2278-8948.

Yari, M. and S.M.S. Mahmoudi, 2010. Utilization of waste heat from GT-MHR for power generation in organic Rankine cycles. Appl. Therm. Eng., 30: 366-375.

Yiwen, L.I., L.I. Yinghong, L.U. Haoyu, Z.H.U. Tao and B. Zhang et al., 2011. Preliminary experimental investigation on $\mathrm{MHD}$ power generation using seeded supersonic argon flow as working fluid. Chin. J. Aeronaut., 24: 701-708. 